\title{
Noise assessment of the small-scale wind farm
}

\author{
Cristian-Gabriel Alionte ${ }^{1, *}$ and Daniel-Constantin Comeaga ${ }^{1}$ \\ ${ }^{1}$ Faculty of Mechanical Engineering and Mechatronics, University Politehnica of Bucharest, RO- \\ 060042, Street Splaiul Independenţei no.313, sector 6, Bucharest, ROMANIA
}

\begin{abstract}
The importance of renewable energy and especially of eolian systems is growing. For this reason, we propose the investigation of an important pollutant - the noise, which has become so important that European Commission and European Parliament introduced Directive 2002/49/CE relating to the assessment and management of environmental noise. So far, priority has been given to very large-scale systems connected to national energy systems, wind farms whose highly variable output power could be regulated by large power systems. Nowadays, with the development of small storage capacities, it is feasible to install small power wind turbines in cities of up to 10,000 inhabitants too. As a case study, we propose a simulation for a rural locality where individual wind units could be used. This specific case study is interesting because it provides a new perspective of the impact of noise on the quality of life when the use of this type of system is implemented on a large scale. This option, of distributed and small power wind turbine, can be implemented in the future as an alternative or an adding to the common systems.
\end{abstract}

\section{Introduction}

Energy production systems based on wind power have had a rather rapid development in the last 50 years being a direct result both of the gradual growth policy of oil prices [1] and pollution reduction policies.

Starting with the time of the energy crisis in 1973 due to the OPEC embargo, developed countries that have a deficit of classical energy resources have been oriented to the renewable energy resources. As a high-success example, Denmark was one of the first countries to develop and implement energy production systems based on wind energy.

Another important argument of wind energy is that it is one of the most environmentally friendly, the energy is cheap, and the investment is recovered much faster than using nuclear energy or coal fired power plants [2].

Globally, currently, there is an acceleration of new wind farms, as can be seen in Fig.1, due to several factors such as the improvement of new technologies, becoming more performant in terms of costs, pollution reduction and production capacity.

So far, priority has been given to very large-scale systems connected to national energy systems, wind farms whose highly variable output power could be regulated by large power systems. At present, with the development of small storage capacities, it is feasible to

\footnotetext{
* Corresponding author: cristian.alionte@upb.ro
} 
install small wind turbines in cities up to 10,000 inhabitants[4]. Few possibilities exist, starting from wind-powered generators obtained by scaling down the most common systems, with huge dimensions, to new devices, with vertical helicoidal blade [4]. A new idea has emerged recently in regions with high noise traffic, reduced with sound absorbing systems, through use of small turbines placed on the top of sound barriers.

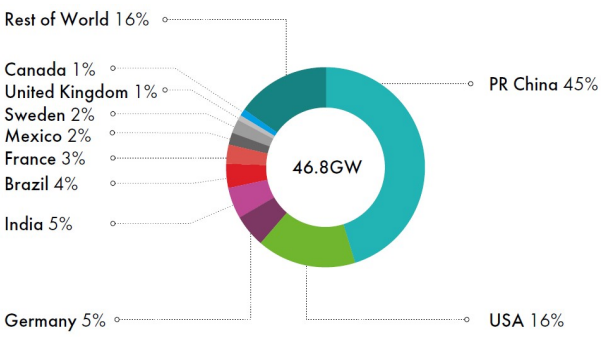

a)

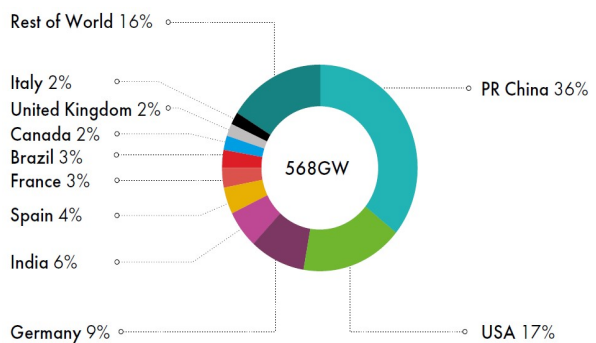

b)

Fig. 1. Development of wind energy sources: a) new installations of onshore wind systems in the year 2018 ; b) total number of onshore wind systems [3].

The noise analysis produced by a wind farm is based on the national and European legislation, mainly the EU directives.

At European level we can emphasize the Directive 2002/49/EC of the European Parliament on the assessment and management of ambient noise, in which the main elements of European noise assessment methods and the mechanisms for reporting the results from national bodies to the European Environmental Agency, with authority in the field, are specified. In the Directive 2002/49/EC it is specified for acoustic planning and noise zoning the obligation to use of $\mathrm{L}_{\mathrm{DEN}}$ and $\mathrm{L}_{\text {night }}$ as noise indicators that can be obtained by calculation or measurements. These indicators are linked with two human factors, according World Health Organization: annoying noise (with $\mathrm{L}_{\mathrm{DEN}}$ ) and sleep disturbance noise (with $\mathrm{L}_{\text {night}}$ ).

But for predictions only the method of calculation can be used, using the formula:

$L_{\mathrm{DEN}}=10 \lg 1 / 24\left(12 \cdot 10^{(\mathrm{Lday} / 10)}+4 \cdot 10^{((\text {Levening }+5) / 10)}+4 \cdot 10^{(\text {Lnight }+10) / 10)}\right)$

where:

$\mathrm{L}_{\text {day }}$ is the average long-term weighted acoustic pressure level for the day period, estimated or measured as an average value during a year, as defined in ISO 1996-2:1987;

$\mathrm{L}_{\text {evening }}$ is the average long-term weighted acoustic power level for the evening period, estimated or measured as an average value during a year, as defined in ISO 1996-2:1987;

$\mathrm{L}_{\text {night }}$ is the average long-term weighted acoustic power level for night period, estimated or measured as an average value during a year, as defined in ISO 1996-2:1987.

In Romania, the Directive was implemented at national level by the Government Decision no. 321/2005 on ambient noise assessment and management, updated in which the standard for calculating the noise parameters is specified, namely SR ISO 9613-2: "Acoustic-Attenuation of sound spread outdoors, Part two: General Method of calculation." Also, as is beforementioned the noise assessment has to use calculations methods which is cheaper than using the monitoring stations.

In this article a small locality, Cochirleanca in Buzau County, Romania, was chosen as a model and several scenarios of wind-producing devices were studied, the output parameters being selected according to the aforementioned directive and national regulations.

The locality was chosen because it is located in an area with wind potential and is representative for rural localities covering a significant area and placed along traffic routes, which adds a significant exposure to road noise. 
The locality Cochirleanca has in WGS system the coordinates $45^{\circ} 12^{\prime} 30^{\prime \prime} \mathrm{N}, 27^{\circ} 2^{\prime} 20^{\prime \prime} \mathrm{E}$ and has a population of 5805 inhabitants (website: http://www.edrc.ro).

\section{Input data}

The calculation method has to include the minimal following elements [6]:

1. Acoustical and physical characteristics of sound pollution sources: type (punctual, linear, volume), size, height, characteristic data of noise emission. In our case we defined two types of sound pollution sources:

-wind turbine which is a punctual source;

-road traffic which is a linear source.

2. Acoustical and physical characteristics of the land type (the existing reflections from the source to the receiver) and especially to green spaces, lakes, parking, asphalt areas. It is also including the topography of the land (height), both the emission points and the receptors (the altitude of each point in the field component is used as a parameter). If the proportion of a type of land is very low (less than $10 \%$ of the total land) for simplification it can be considered either the land is fully reflective or absorbent. In our case we have:

- data for land type, (Fig.2.a), from Open Street Maps (website: https://www.openstreetmap.org);

- data for land model, (land height points) from Shuttle Radar Topography Mission (website: https://lpdaac.usgs.gov).

3. Acoustical and physical characteristics of obstacles (dimensions, shape, material), buildings, bridges, walls. In our case we defined:

- data for buildings (in Fig.2.b)- Open Street Maps (website: https://www.openstreetmap.org);

- we made a parapet on both sides of the road, on we considered that a vertical wind turbine is built.

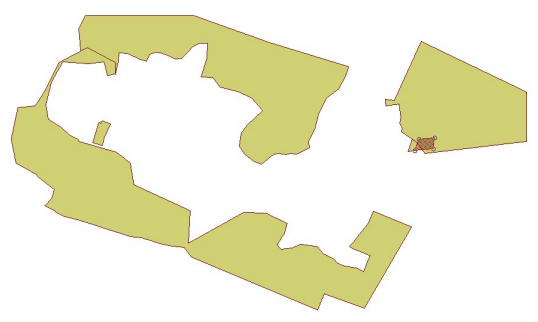

a)

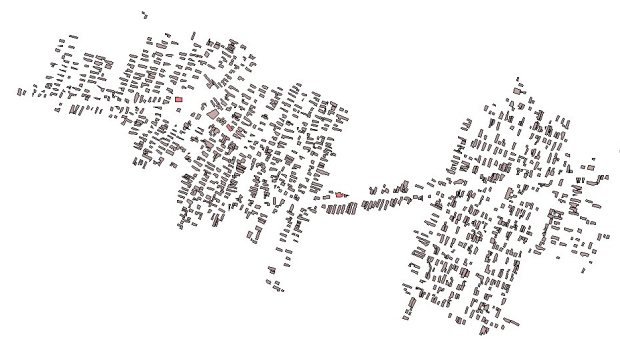

b)

Fig. 2. GIS data used in the model : a) land; b) buildings.

4. Receivers characteristics. The receivers can be receptors distributed:

- evenly over the entire surface of the calculation model (as we present in the calculation maps in this article);

- at the front level (relevant only for high-rise buildings with a population distributed vertically);

- evenly distributed inside buildings (to determine the affected population).

For modelling and calculation, NoiseModelling software was used [7] where all the elements above mentioned make a GIS database ( Geographic Information System) comprising the geometric elements and attributes of each element. The calculation model includes: 
-Weather statistical data for the whole year. For our model all weather statistical data (temperature - Fig.3a), humidity, wind speed and wind direction Fig. 3 b) are from Meteoblue website (website https://www.meteoblue.com).

-calculation method (for industry or for road);

-the grid size (10mx10m in our case);

-the number of reflections of the acoustical ray with the model objects ( 2 in our case);

-the day intervals (Day from: 07h-19h, Evening:19h-23h and Night:23h-07h);

-the tracer method(fast ray, ray and beam).

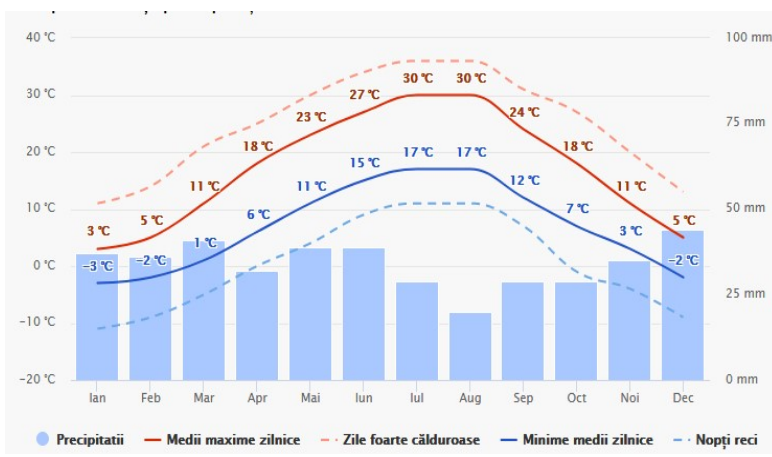

a)

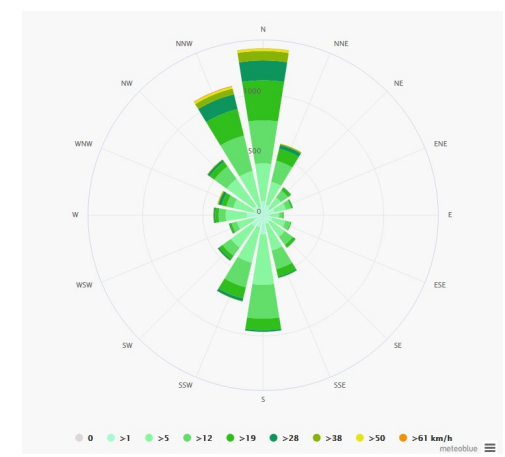

b)

Fig. 3. Weather data used in the model (website https://www.meteoblue.com): a) temperature and humidity; b) wind speed and direction

\section{Noise assessment}

In the article, we have analyzed the following scenarios, depending on the size and distribution of eolian generating systems:

- Scenario 1 - Large size wind turbines - producing $750 \mathrm{~kW}$ with a $45 \mathrm{~m}$ rotor diameter (including blades);

- Scenario 2 - Small size wind eolian farm - consisting of 70 independent systems producing each $10 \mathrm{~kW}$ with a $3 \mathrm{~m}$ rotor diameter. The distance between the turbines is $300 \mathrm{~m}$ and has been considered the maximum number that could be distributed in the calculation area.

- Scenario 3 - Small horizontal wind turbines - which produce under $1 \mathrm{~kW}$ with $1 \mathrm{~m}$ rotor diameter. There were considered 750 wind systems to reach the minimum energy level generated in Scenario 1, uniformly distributed on the area.

- Scenario 4 - Small vertical wind turbines - producing less than $1 \mathrm{~kW}$ located at the road parapets.

For each scenario, calculations were made and the values of noise indicators are graphically displayed in the form of noise maps, in which the calculation area is divided into equal areas of $10 \mathrm{~m} \times 10 \mathrm{~m}$ each and for each noise level band of $5 \mathrm{~dB}$ a unique color is used (the color code is recommended in the regulations).

\subsection{Scenario 1 - Large size wind turbines}

In the first scenario was considered the case where a single large wind is used. The wind turbine is assumed to be on a $50 \mathrm{~m}$ tower and can be acoustically modeled as an omnidirectional source with the sound power level of $102 \mathrm{~dB}(\mathrm{~A})$ [5]. The location of the wind system was considered more than $500 \mathrm{~m}$ from the nearest dwelling. As can be seen in 
the Fig. 4, the impact is relevant at the buildings level in the area with immission over $75 \mathrm{~dB}$.

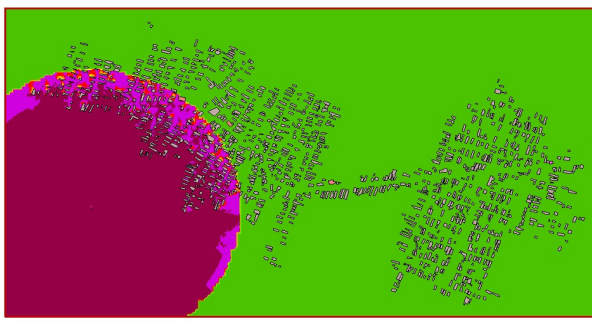

a)

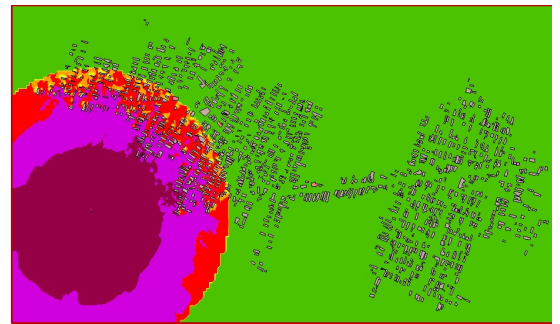

b)

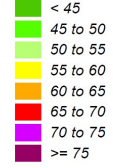

c)

Fig. 4. Noise Map considering the first scenario: a) $\mathrm{L}_{\mathrm{DEN}}$ indicator level; b) $\mathrm{L}_{\text {night }}$ indicator level ; c) graphical correspondence using the color code, the values are in $\mathrm{dB}$

\subsection{Scenario 2 - Small size wind eolian farm}

In this case we consider a wind farm consisting of Bergey BWC Excel 10 (website: https://en.wind-turbine-models.com) type systems, acoustically modeled as omnidirectional source with the sound power level of $100 \mathrm{~dB}(\mathrm{~A})$ (website: http://www.wind-works.org). The farm is split in two, one location is in the South West of the map and the second is in North East, because there is a minimum distance limitation between the turbines. In this case you can see that the impact is much stronger than the one in Scenario 1.

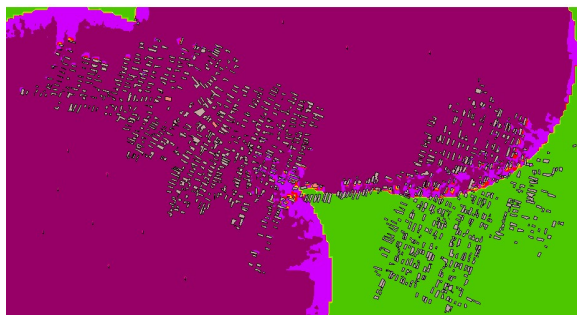

a)

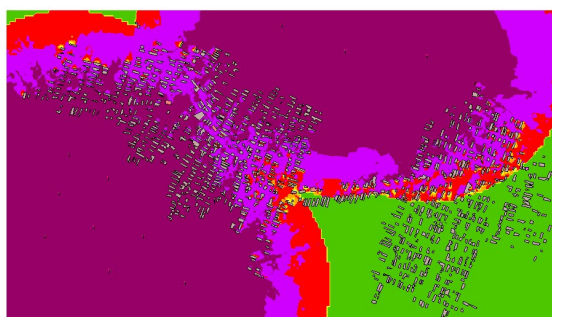

b)

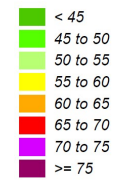

c)

Fig. 5. Noise Map considering the second scenario: a) $\mathrm{L}_{\mathrm{DEN}}$ indicator level; b) $\mathrm{L}_{\text {night }}$ indicator level ; c) graphical correspondence using the color code, the values are in $\mathrm{dB}$

\subsection{Scenario 3 - Small Wind individual eolian turbines}

In this case we consider that each dwelling has an individual wind turbine, Bergey BWC Excel 10 (website: https://en.wind-turbine-models.com) type, acoustically modeled as an omnidirectional source with the sound power level of $60.79 \mathrm{~dB}(\mathrm{~A})[4]$

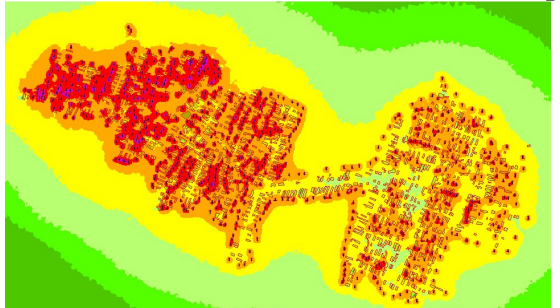

a)

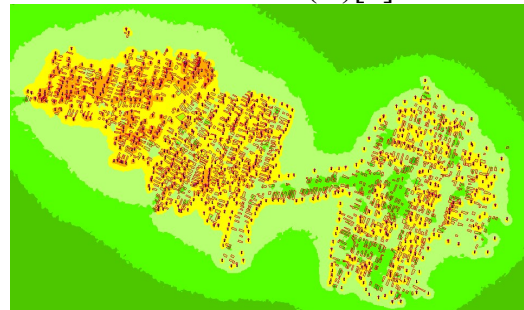

b)

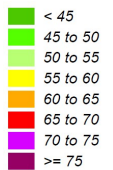

c)

Fig. 5. Noise Map considering the third scenario: a) $L_{\text {DEN }}$ indicator level; b) $L_{\text {night }}$ indicator level ; c) graphical correspondence using the color code, the values are in $\mathrm{dB}$ 


\subsection{Scenario 4 - Small Wind vertical eolian turbines}

As final scenario, we have considered that we can use some vertical wind turbines which are located on the parapet of the road. They are put in motion by air currents generated by the vehicles moving along the road.

Due to the relevant road traffic through the locality, the inclusion of the population in the legally accepted immission intervals requires the use of noise reduction solutions. The possibility of using acoustic insulating panels, modified according to new concepts, that propose the recovery of energy of air currents produced in the circulation of motor vehicles through the integration of micro-turbines in panels has been analyzed. Although with a high manufacturing complexity (it is necessary to use a construction that integrates the turbines but does not allow the propagation of the sound, the easiest placement of the turbines being in the upper area of the panels, where usually are placed devices for reducing sound diffraction) the solution is interesting from the energy point of view and allows faster recovery of the investment. At the same time, by placing the walkways, you can remove the speed restrictions through the locality. In this case, according to Government Decision No. 321/2005 updated the method for calculating the noise parameters "NMPB Routes-96 (SETRA-CERTU-LCPC-CSTB)", a French national method of calculation, part of the French standard XPS 31-133, was used for assessment of noise generated by car traffic.

From the street network of the locality, we considered only the main street (DJ220). The input data collected on April 12, 2019, is:

- The traffic data

- Small vehicles (under $<3,5 \mathrm{~kg}$ ) Day-75, evening-40, night-10;

- Large vehicles (>3.5 kg), day-30, evening-15, night-5;

- Vehicle speed - $50 \mathrm{~km} / \mathrm{h}$;

- the surface is asphalt without pits;

- traffic is considered to be pulse flow type.

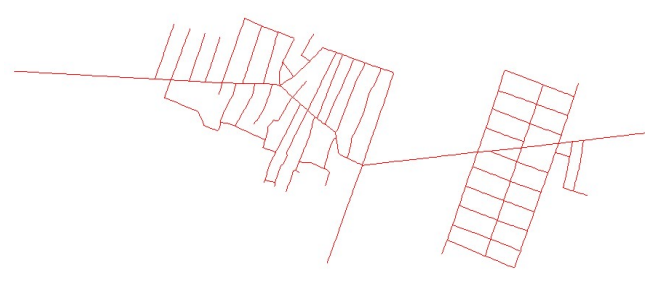

a)

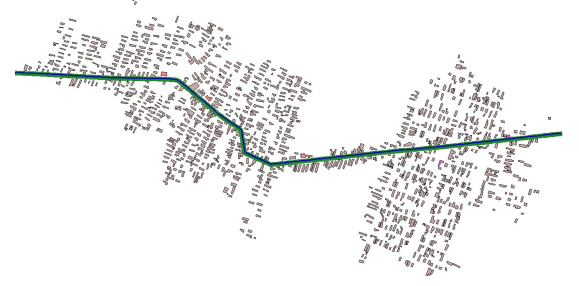

b)

Fig. 6. The road network of the locality : a) full road network; b) the calculation model with DJ220

As could be seen in Figure 7, the impact of the noise produced by the road is an important one, requesting solutions for protecting the dwellings and population.

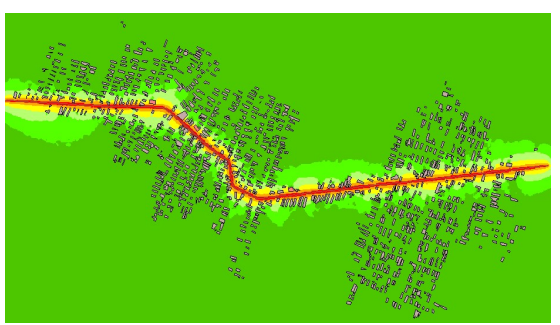

a)

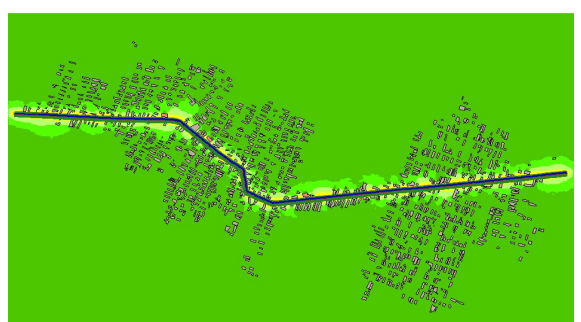

b)

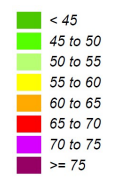

c)

Fig. 7. Noise Map considering the road noise: a) $\mathrm{L}_{\mathrm{DEN}}$ indicator level; b) $\mathrm{L}_{\text {night }}$ indicator level ; c) graphical correspondence using the color code, the values are in $\mathrm{dB}$ 
As a result of the application of the panels that support micro-turbines, a reduction in the noise produced by road traffic may be observed (Fig. 8).

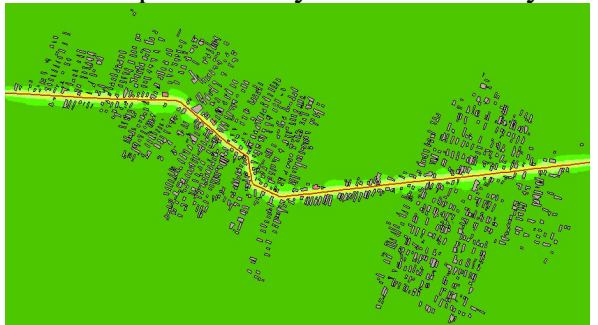

a)

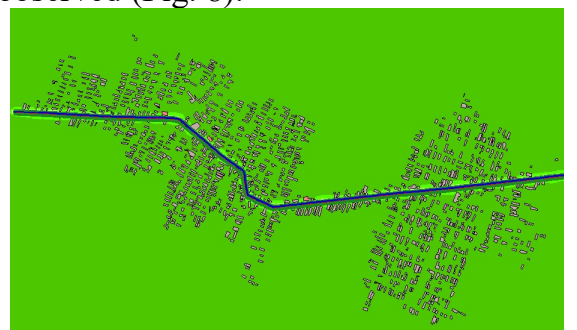

b)

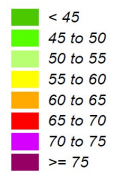

c)

Fig. 8. Noise Map considering the road noise and panels: a) $L_{D E N}$ indicator level; b) $L_{\text {night }}$ indicator level ; c) graphical correspondence using the color code, the values are in $\mathrm{dB}$

The microturbines were modeled separately as a network of omnidirectional noise sources of under $40 \mathrm{~dB}$ [8] placed at height on the panels. A separate noise map has been calculated for these (Figure 9).

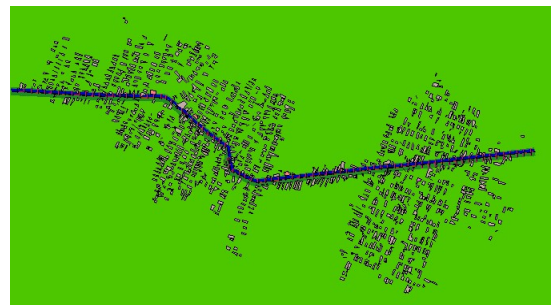

a)

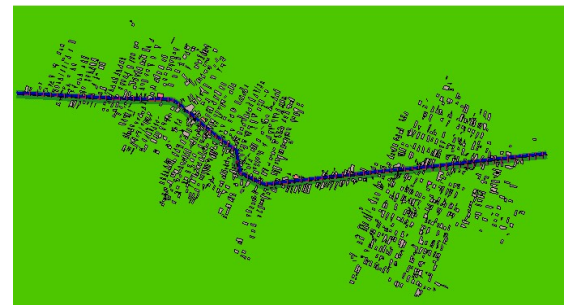

b)

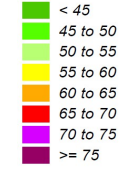

c)

Fig. 9. Noise Map considering the micro-turbines: a) $\mathrm{L}_{\mathrm{DEN}}$ indicator level; b) $\mathrm{L}_{\text {night }}$ indicator level ; c) graphical correspondence using the color code, the values are in $\mathrm{dB}$

Noise maps for road traffic and microturbines were summed up and the exposed population estimated (Figure 10).

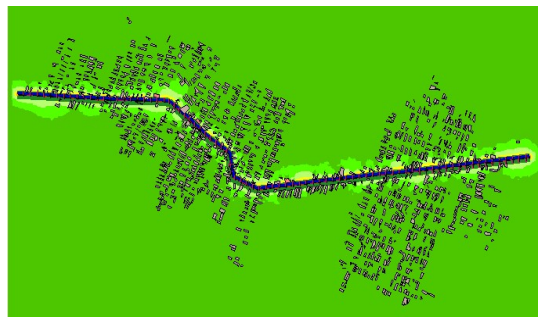

a)

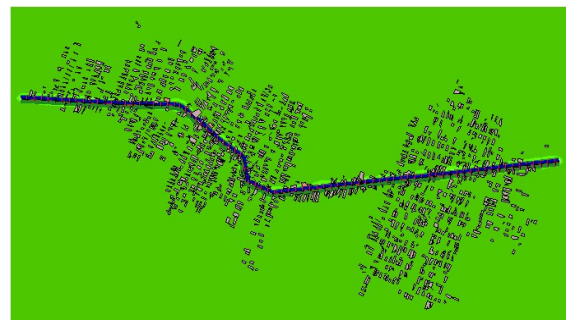

b)

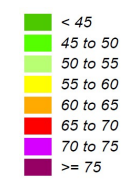

c)

Fig. 10. Cumulated Noise Map considering the road noise with panels and microturbines: a) $L_{D E N}$ indicator level; b) $\mathrm{L}_{\text {night }}$ indicator level ; c) graphical correspondence using the color code, the values are in $\mathrm{dB}$

\section{Results and conclusions}

The maximum noise values for Romania, set according to the Ministry Order MMDD/MT/MSP/MIRA Nr. 152/558/1119/532/2008 (MO No. 531/15.07.2008), are presented in table 1: 
Table 1. Noise limit values

\begin{tabular}{|l|c|c|}
\hline Noise source & $\begin{array}{c}\text { Maximum Allowed Values, } \\
\text { computed on a 24-hour basis } \\
\mathrm{L}_{\text {DEN }} \mathrm{dB}(\mathrm{A})\end{array}$ & $\begin{array}{c}\text { Maximum Allowed } \\
\text { Values during Night } \\
\mathrm{L}_{\text {night }} \mathrm{dB}(\mathrm{A})\end{array}$ \\
\hline Streets, roads and highways & 65 & 50 \\
\hline Industrial Areas & 60 & 50 \\
\hline
\end{tabular}

Using the calculation method, we have obtained the affected population, divided in bands of $5 \mathrm{~dB}$ range of noise, as presented in table 2 . As can be seen, for common windturbines, in terms of 24 hours noise the weakest variant consists of Scenario 2 - the $\mathrm{L}_{\mathrm{DEN}}$ level; scenario 3 is the weakest night values - the $\mathrm{L}_{\text {night }}$ level. We can say that using only one wind turbine is the best case when we take into consideration the efficiency, the cost and the pollution.

Table 2. Comparison of affected inhabitants

\begin{tabular}{|l|c|c|c|c|c|c|}
\hline $\begin{array}{c}\text { Noise interval } \\
(\mathrm{dB})\end{array}$ & \multicolumn{2}{|c|}{$\begin{array}{c}\text { Affected inhabitants } \\
\text { Scenario 1 }\end{array}$} & \multicolumn{2}{c|}{$\begin{array}{c}\text { Affected inhabitants } \\
\text { Scenario 2 }\end{array}$} & \multicolumn{2}{c|}{$\begin{array}{c}\text { Affected inhabitants } \\
\text { Scenario 3 }\end{array}$} \\
\hline & $\mathrm{L}_{\text {DEN }}$ & $\mathrm{L}_{\text {night }}$ & $\mathrm{L}_{\text {DEN }}$ & $\mathrm{L}_{\text {night }}$ & $\mathrm{L}_{\text {DEN }}$ & $\mathrm{L}_{\text {night }}$ \\
\hline$<45$ & 4449 & 4449 & 1408 & 1408 & 0 & 11 \\
\hline $45-50$ & 0 & 1 & 0 & 8 & 0 & 577 \\
\hline $50-55$ & 1 & 11 & 0 & 0 & 284 & 2097 \\
\hline $55-60$ & 5 & 16 & 8 & 8 & 1611 & 2490 \\
\hline $60-65$ & 11 & 160 & 8 & 33 & 2690 & 604 \\
\hline $65-70$ & 74 & 632 & 24 & 536 & 1168 & 25 \\
\hline $70-75$ & 450 & 480 & 250 & 1824 & 52 & 0 \\
\hline $75>$ & 814 & 55 & 4107 & 1988 & 0 & 0 \\
\hline $\begin{array}{l}\text { Population } \\
\text { above the limit }\end{array}$ & 1349 & 1354 & 4389 & 4389 & 3910 & 5216 \\
\hline
\end{tabular}

We must consider the fact that the acoustic level of the eolian system is valid at strong wind exceeding $50 \mathrm{~km} / \mathrm{h}$, which is considered the most disadvantageous case.

The scenario 4 uses only secondary the wind because the currents are produced by road traffic. This is an advantage because this is independent of the weather conditions. Another advantage is a small noise pollution, as can be seen in table 3 and, even more, the panel is isolating a part of the noise generated by traffic. The disadvantage lies in a reduced efficiency and therefore in a higher energy production price.

Table 3. Comparison of affected inhabitants

\begin{tabular}{|l|c|c|c|c|}
\hline $\begin{array}{c}\text { Noise interval } \\
(\mathrm{dB})\end{array}$ & \multicolumn{2}{|c|}{$\begin{array}{c}\text { Affected inhabitants } \\
\text { without panel }\end{array}$} & \multicolumn{2}{c|}{$\begin{array}{c}\text { Affected inhabitants with } \\
\text { panel and micro-wind turbines }\end{array}$} \\
\hline & $\mathrm{L}_{\text {DEN }}$ & $\mathrm{L}_{\text {night }}$ & $\mathrm{L}_{\text {DEN }}$ & $\mathrm{L}_{\text {night }}$ \\
\hline$<45$ & 3947 & 4759 & 4387 & 4890 \\
\hline $45-50$ & 547 & 252 & 405 & 670 \\
\hline $50-55$ & 301 & 766 & 164 & 230 \\
\hline $55-60$ & 456 & 28 & 656 & 15 \\
\hline $60-65$ & 555 & 0 & 192 & 0 \\
\hline $65-70$ & 0 & 0 & 0 & 0 \\
\hline $70-75$ & 0 & 0 & 0 & 0 \\
\hline $\begin{array}{l}\text { Population } \\
\text { above the limit }\end{array}$ & 555 & 0 & 192 & 0 \\
\hline
\end{tabular}

In the case of small cities with limited areas, analyzing the affected population, the costs of implementation and from the practical point of view, we can say that the use of large 
turbines is the most efficient of existing turbine solutions. An interesting solution especially for cities along high traffic roads that produce high pollution is the use of acoustic insulating panels incorporating micro-turbine solutions which can be implemented in different architectural cityscapes for a better visual impact. It achieves both a strong reduction in street noise and the possibility of removing speed restrictions, so a reduction of pollution from thermal motors, as well as a generation of electricity. These micro-turbines are much easier to install and maintain than large turbines without the need for specialized personnel.

These types of micro-turbines will be the subject of additional studies, analyzing the possibility of combining with asphalt-mounted energy recovering systems (using piezoelectric materials).

\section{References}

1. V. Lapčík, Wind Farm - Technical Regulations, Potential Estimation and Siting Assessment (InTech 2011)

2. S. Mathew, Wind energy. Fundamentals, Resource Analysis and Economics (Springer 2006)

3. M. Dyrholm, Global wind report - 2018 (GWEC 2018)

4. J. Taylor, C. Eastwick, C. Lawrence, R. Wilson, Ren. En., 55 (2013)

5. A.L. Rogers, J. F. Manwell, S. Wright, Wind Turbine Acoustic Noise (White paper, 2006)

6. G. Licitra, Noise Mapping in the EU - Models and Procedures (CRC Press 2013)

7. E. Bocher, G. Guillaume, J. Picaut, G. Petit, N. Fortin, ISPRS Int. J. Geo-Inf. 8, 3 (2019)

8. J. D. M. Botha, H. Rice, A novel method of vertical axis wind turbine noise prediction, (EuroNoise 2015) 